\title{
A practical demonstration of the computational benefits of biophysical diversity among neurons
}

\author{
Shreejoy J Tripathy ${ }^{1 *}$, Krishnan Padmanabhan², Nathan N Urban ${ }^{1,2}$ \\ From Nineteenth Annual Computational Neuroscience Meeting: CNS*2010 \\ San Antonio, TX, USA. 24-30 July 2010
}

Across a variety of brain areas, physiological characterizations of neurons have revealed that neurons of the same subtype often display different biophysical properties from one another. Here we propose that when considering a population of neurons these inter-neuronal differences can be utilized by the population to enhance encoding of a stimulus. Specifically, we demonstrate that a population of neurons with heterogeneous feature selectivity across the population can represent more about a stimulus than a population of neurons with identical feature selectivity.

Using a paradigm of an identical frozen noise current injection stimulus delivered to a population of neurons, we simulated the responses of populations of neurons with differing degrees of heterogeneity in their feature selectivity. We simulated neurons using the Linear-Nonlinear-Poisson (LNP) neuron model and constructed neurons selective to different features of the stimulus by varying the stimulus filter of each LNP neuron.

To calculate the information encoded in the spike responses of different populations of neurons, we used information theoretic measures as well as optimal Bayesian stimulus reconstruction methods. Stimulus reconstruction methods are particularly useful in this context because they allow us to visualize which particular stimulus features are able to be encoded by different populations. We found that stimulus reconstructions computed from responses of heterogeneous neurons were more accurate than responses from homogenous neurons.

Finally, we recorded spike responses in vitro from a number of mitral cells from the mouse olfactory bulb while stimulating each cell with an identical current injection stimulus. Based on the similarity of each

\footnotetext{
* Correspondence: stripathy@cmu.edu

${ }^{1}$ Center for the Neural Basis of Cognition, Carnegie Mellon University, Pittsburgh, PA 15213, USA
}

neuron's spike triggered average, an indication of the neuron's feature selectivity, we grouped neurons into virtual homogenous and heterogeneous populations. As above we found that populations composed of heterogeneous neurons encoded more information about the stimulus input than homogenous populations.

Though inter-neuronal diversity is often thought of as a negative consequence of the inability of biology to make identical copies of the same neuron, our results indicate that neuronal diversity may in fact be utilized positively by the brain.

\section{Author details}

${ }^{1}$ Center for the Neural Basis of Cognition, Carnegie Mellon University, Pittsburgh, PA 15213, USA. ²Department of Biology, Carnegie Mellon University, Pittsburgh, PA 15213, USA.

Published: 20 July 2010

doi:10.1186/1471-2202-11-S1-P164

Cite this article as: Tripathy et al: A practical demonstration of the computational benefits of biophysical diversity among neurons. BMC Neuroscience 2010 11(Suppl 1):P164.
Submit your next manuscript to BioMed Central and take full advantage of:

- Convenient online submission

- Thorough peer review

- No space constraints or color figure charges

- Immediate publication on acceptance

- Inclusion in PubMed, CAS, Scopus and Google Scholar

- Research which is freely available for redistribution

Submit your manuscript at www.biomedcentral.com/submit
C Biomed Central 